\title{
Characterization of Fiber Types in Different Muscles of the Hindlimb in Female Weanling and Adult Wistar Rats
}

\author{
Anabelle Silva Cornachione ${ }^{1}$, Priscila Cação Oliveira Benedini-Elias ${ }^{1}$, Juliana Cristina Polizello ${ }^{1}$, \\ Leonardo César Carvalho ${ }^{1}$ and Ana Cláudia Mattiello-Sverzut ${ }^{1}$
}

${ }^{1}$ Department of Biomechanics, Medicine and Rehabilitation of the Locomotor Apparatus, Faculty of Medicine of Ribeirão Preto, University of São Paulo at Ribeirão Preto, Brazil

Received October 19, 2010; accepted December 22, 2010; published online March 30, 2011

\begin{abstract}
We analyzed lesser diameter and distribution of fiber types in different skeletal muscles from female Wistar rats using a histoenzymology Myofibrillar Adenosine Tri-phosphatase (mATPase) method. Fragments from muscles were frozen and processed by mATPase in different $\mathrm{pH}$. Adult and weanling rat soleus muscles presented a predominance of type I fibers and larger fiber diameters. In the plantar muscle in adult rats, the type IIB fibers demonstrated greater lesser diameter while in the weanling animals, types I and IIB fibers were larger. The plantar muscle of animals of both ages was composed predominantly of the type IID fibers. The type IID fibers were observed in similar amounts in the lateral gastrocnemius and the medial gastrocnemius muscles. Type IIB fibers showed predominance and presented higher size in comparison with other types in the EDL muscle. The present study shows that data on fiber type distribution and fiber lesser diameter obtained in adult animals cannot always be applied to weanling animals of the same species. Using the mATPase, despite the difficult handling, is an important tool to determine the different characteristics of the specific fibers in the skeletal muscle tissue.
\end{abstract}

Key words: skeletal muscle, fibers type, histoenzymology technique, weanling rats, adult rats

\section{Introduction}

A unique feature of skeletal muscle is that it is composed of different types of muscle fibers that are responsible for a variety of functional capabilities. The velocity of muscle contraction is directly related to myofibrillar adenosine tri-phosphatase (mATPase) activity, which in turn is closely associated with distinct myosin isoforms. Adult skeletal muscles have four representative myosin heavy chain isoforms (MHCIIa, IIb, IId and I), although hybrid fibers have heterogeneous isoform composition (MHCIIb+MHCIId/x, MHCIId/x+MHCIIa or MHCIIa+MHCI) [21]. In 1969, Guth and Samaha [14] proposed a method of histochemical

Correspondence to: Profa. Dr. Ana Cláudia Mattiello-Sverzut, Department of Biomechanics, Medicine and Rehabilitation of the Locomotor Apparatus, Faculty of Medicine of Ribeirão Preto, University of São Paulo, Bandeirantes Av, 3900, Ribeirão Preto, SP 14049-900.

E-mail: acms@fmrp.usp.br and anabelle_cornachione@hotmail.com coloring of muscle tissue utilizing different acid and basic pre-incubation media. Based on labelling of myosin activity, fibers were classified in type I and type II, and also in subtypes IIA, IID/X and IIB [2, 32, 33].

Comparative studies in normal muscle have shown that the enzymatic and morphometric classification of fibers vary according to the species $[7,20]$. Some variation can also occur in the sample to sample in the same muscle [11, 17] and fibers to fibers in the same sample. A clear example of these different enzymatic and morphometric aspects was documented by Staron et al. [34] when they studied four different muscles of the hindlimb of male Fischer 344 rats.

Due to an increased demand and functional diversity imposed during development of the animals, changes in mATPase enzyme activity determine transitional changes between the MHC isoforms, thus defining morphological and functional maturation of muscle fibers [1]. There are many factors related to maturation that contribute to the differentiation of the muscle fibers; changes in the neuro- 
muscular activity, the maturation of the neuromuscular junction, changes in the excitation-contraction coupling mechanism, and an increase in the circulating levels of the thyroid hormone [1, 25, 37]. However, in the adult animal these adaptations are already established, and the contractile characteristics of muscles are established by the quantity of fiber types. The morphological comparison between different phases of muscle development is of importance to verify the principal muscle adaptations that occur with aging.

There are just a few studies that have addressed fiber type classification in biomechanically distinct muscles of female Wistar rats, especially in animals of different ages. The purpose of this study was to determine the mean lesser diameter and distribution of fiber types using diverse skeletal muscles of the female weanling and adult Wistar rats using histoenzymological myofibrillar mATPase technique in different hydrogen-ion potential.

\section{Materials and Methods}

This study was performed with six (6) adult female Wistar rats, 70 days old, and three (3) weanling female Wistar rats, 21 days old. The average weight of the both groups was $285 \mathrm{~g}$ and $59 \mathrm{~g}$, respectively. The animals were raised in the Central Animal House of the Ribeirão Preto Campus of the University of São Paulo and had free access to water and pelleted food. Muscles to be analyzed were removed after sacrifice with an overdose of Thyopental.

A distal incision was made along the tibia of the right hindlimb, close to the ankle joint, exposing the soleus, medial (MG) and lateral (LG) gastrocnemius, extensor digitorum longus (EDL) and the plantar muscles of the groups. Soleus and plantar muscles were isolated in the weanling rats following the same procedure. All muscles were then removed, and muscle fragments were covered in talcum powder, frozen in liquid nitrogen $\left(-196^{\circ} \mathrm{C}\right)$ and stored at $-80^{\circ} \mathrm{C}$ following routine procedures performed in the Neuropathology Laboratory, Pathology Department, Faculty of Medicine of Ribeirão Preto, University of São Paulo, USP. The study was approved by the Ethics in Animal Experimentation Committee of the Faculty of Medicine of Ribeirão Preto (protocol n ${ }^{\circ}$ s: 042/2007 and 041/2007).

Muscle transversal sections $(5 \mu \mathrm{m})$ were cut in a Leica $\mathrm{CM} 1850 \mathrm{UV}$ Cryotome at $-25^{\circ} \mathrm{C}$ and collected on glass slides, $24 \times 32 \mathrm{~mm}$. Myofibrillar Adenosine Tri-phosphatase (mATPase (E.C.2.1.3.5.7.9.1) activity was determined after pre-incubation in acid and basic $\mathrm{pH}$ conditions according classic literature [6, 14]. Minor adjustments in pre-incubation $\mathrm{pH}$ were occasionally made for optimizing the sample staining intensities. For the basic conditions, the $\mathrm{pH}$ range was between 10.5 and 9.2, modified in 0.1 intervals. For the acidic conditions, the $\mathrm{pH}$ range was between 4.8 and 4.1 , also modified in 0.1 intervals. The final $\mathrm{pH}$ values adopted for each muscle are shown in Table 1 .

After determining the optimal $\mathrm{pH}$ for ATPase activity the muscles were characterized as follows, according to their fibers: 1-Adult, Plantar - pure type I fibers (TIF), type IIA
Table 1. Different values of $p H$ used in the MATPase technique, in the different muscles studied in female Wistar rats

\begin{tabular}{llcc}
\hline & \multicolumn{2}{c}{ Acid pH } & Básic pH \\
\hline SOL $^{(\mathrm{W})}$ & 4.3 & 4.6 & 9.8 \\
$\mathrm{PLA}^{(\mathrm{W})}$ & 4.4 & 4.6 & 10.4 \\
$\mathrm{GLD}^{(\mathrm{A})}$ & 4.3 & 4.6 & 9.9 \\
$\mathrm{GMD}^{(\mathrm{A})}$ & 4.3 & 4.6 & 9.9 \\
$\mathrm{SOL}^{(\mathrm{A})}$ & 4.3 & 4.6 & 9.4 \\
$\mathrm{PLA}^{(\mathrm{A})}$ & 4.3 & 4.6 & 10.4 \\
$\mathrm{EDL}^{(\mathrm{A})}$ & 4.3 & 4.6 & 10.3 \\
\hline
\end{tabular}

SOL ${ }^{(\mathrm{W})}$, soleus in weanling animals; $\mathrm{PLA}^{(\mathrm{W})}$, plantar in weanling rats; $\mathrm{GLD}^{(\mathrm{A})}$, lateral profound gastrocnemius in adult animals; $\mathrm{GMD}^{(\mathrm{A})}$, medial profound gastrocnemius in adult animals; $\mathrm{SOL}^{(\mathrm{A})}$, Soleus in adult animals; PLA ${ }^{(\mathrm{A})}$, plantar in adult animals; EDL ${ }^{(\mathrm{A})}$, extensor digitorum longus in adult animals.

(TIIAF), type IID (TIIDF), and type IIB (TIIBF); hybrid type IIC fibers (TIICF). Soleus - pure fibers (TIF, TIIAF and TIIDF); hybrid fibers (TIICF, TIIACF and TIIADF). EDL - pure fibers (TIF, TIIAF, TIIDF and TIIBF); hybrid fibers (TIICF and TIIADF). Medial and lateral gastrocnemius, pure fibers (TIF, TIIAF, TIIDF and TIIBF); hybrid fibers (TIICF, TIIADF). 2-Weanling, Soleus - pure fibers (TIF, TIIAF and TIIDF); hybrid fibers (TIICF, TIIACF and TIIADF). Plantar - pure fibers (TIF, TIIAF, TIIDF and TIIBF); hybrid fibers (TIICF). Table 2 describes the specific fiber types and color intensities obtained with the mATPase reactions in different $\mathrm{pH}$. The fiber types were classified as pure or hybrid fibers using the comparison between the slides incubated in acids and basic $\mathrm{pH}$ as proposed by Brooke and Kaiser [6], Pette and Staron [23] and Stephenson [35].

Morphometric analysis of the proportion and lesser diameter of fibers was conducted with the software QualiView-Atonus and the images captured though an optical microscope (Leica DM 2500) equipped with a digital video camera (Leica DFC 300FX) connected to a computer. The lesser diameter was used in this study because it allows for the correction of distortions due to imperfect transversal sectioning of the fibers [10]. Lesser diameter was determined by measurements of approximately 200 fibers/ fragment. Proportion analysis was obtained by counting the different types of fibers in images collected from three random fields in samples of each animal. Statistical analysis of lesser diameters of fiber types were conducted using ANOVA followed by the Tukey-Kramer post-hoc analysis and proportion of fibers were analyzed by mixed-effects linear models, using the SAS software version 9, with the level of significance set at 0.05 .

\section{Results}

Figure 1 presents morphological aspects of the different fiber types in different $\mathrm{pH}$ for each muscle. The sections that were pre-incubated in $\mathrm{pH} 4.6$ show an extensive variety of fiber types that compose the different muscles, demonstrat- 
Table 2. Spectrum of color intensities using mATPase reaction in different $p H$ according to the muscles investigated in the female Wistar rats

\begin{tabular}{|c|c|c|c|c|c|c|c|}
\hline & & \multicolumn{6}{|c|}{ Color intensity of the different fiber type } \\
\hline & & TIF & TIICF & TIIAF & TIIADF & TIIDF & TIIBF \\
\hline \multirow{3}{*}{$\mathrm{SOL}^{(\mathrm{W})}$} & $\mathrm{pH} 9.8$ & - & ++ & ++ & ++ & $\varnothing$ & $\varnothing$ \\
\hline & $\mathrm{pH} 4.6$ & ++ & + & - & \pm & $\varnothing$ & $\varnothing$ \\
\hline & $\mathrm{pH} 4.3$ & ++ & \pm & - & - & $\varnothing$ & $\varnothing$ \\
\hline \multirow{3}{*}{$\operatorname{PLA}^{(\mathrm{W})}$} & $\mathrm{pH} 10.4$ & - & ++ & ++ & $\varnothing$ & ++ & + \\
\hline & $\mathrm{pH} 4.6$ & ++ & + & - & $\varnothing$ & \pm & \pm \\
\hline & $\mathrm{pH} 4.4$ & ++ & \pm & - & $\varnothing$ & - & - \\
\hline \multirow{3}{*}{$\mathrm{GLD}^{(\mathrm{A})}$} & pH 9.9 & - & $\varnothing$ & ++ & ++ & ++ & $\varnothing$ \\
\hline & $\mathrm{pH} 4.6$ & ++ & $\varnothing$ & - & \pm & + & $\varnothing$ \\
\hline & $\mathrm{pH} 4.3$ & ++ & $\varnothing$ & - & - & - & $\varnothing$ \\
\hline \multirow{3}{*}{$\mathrm{GMD}^{(\mathrm{A})}$} & pH 9.9 & - & $\varnothing$ & ++ & ++ & ++ & + \\
\hline & $\mathrm{pH} 4.6$ & ++ & $\varnothing$ & - & \pm & + & + \\
\hline & $\mathrm{pH} 4.3$ & ++ & $\varnothing$ & - & - & - & - \\
\hline \multirow{3}{*}{$\mathrm{SOL}^{(\mathrm{A})}$} & $\mathrm{pH} 9.4$ & - & ++ & ++ & ++ & $\varnothing$ & $\varnothing$ \\
\hline & $\mathrm{pH} 4.6$ & ++ & + & - & \pm & $\varnothing$ & $\varnothing$ \\
\hline & pH 4.3 & ++ & \pm & - & - & $\varnothing$ & $\varnothing$ \\
\hline \multirow{3}{*}{$\operatorname{PLA}^{(\mathrm{A})}$} & $\mathrm{pH} 10.4$ & - & ++ & ++ & $\varnothing$ & ++ & + \\
\hline & $\mathrm{pH} 4.6$ & ++ & + & - & $\varnothing$ & \pm & \pm \\
\hline & $\mathrm{pH} 4.3$ & ++ & \pm & - & $\varnothing$ & - & - \\
\hline \multirow{3}{*}{$\operatorname{EDL}^{(\mathrm{A})}$} & pH 10.3 & - & + & ++ & $\varnothing$ & ++ & + \\
\hline & pH 4.6 & ++ & + & - & $\varnothing$ & \pm & \pm \\
\hline & $\mathrm{pH} 4.3$ & ++ & \pm & - & $\varnothing$ & - & - \\
\hline
\end{tabular}

- clear; \pm intermediate clear; + intermediate dark; ++ dark; Ø fiber type unidentified.

ing a wide spectrum between clear, dark and intermediate colors. The sections that had more acidic $\mathrm{pH}$ values (4.4 and 4.3) were used to confirm type IIC fibers that presented intermediate coloration and also to differentiate type IIAC fibers and type IIAD fibers that presented intermediate clear and clear coloration, respectively. For the classification of the type IIB fibers and type IID fibers, alkaline $\mathrm{pH}$ was used, as well as comparisons with the findings of the $\mathrm{pH}$ 4.6 sections.

Table 3 shows mean and the standard deviation values of the lesser fibers diameter of the adult and weanling animals. The TIF in the soleus muscle of weanling rats have the largest mean values when compared to other fibers (Table 3). The plantar muscle in the same group also has TIF and TIIBF with mean lesser diameters significantly larger than TIICF and TIIAF (Table 3). In adult animals, different types of fibers in the soleus muscle were characterized by similar mean lesser diameter values. Only TIICF showed values significantly lower than TIF. Type IIB fibers in the plantar muscles presented larger mean lesser diameter than TIF and TIIAF. However, they were not larger than TIIDF. Similarly, TIIBF in EDL muscles showed significantly higher mean lesser diameter than others fibers, except TIIDF. Fibers in the lateral gastrocnemius muscle had similar values of the mean lesser diameter, but in the medial portion the TIF and TIIDF showed values significantly higher than TIIAF.
The proportions of both pure and hybrid fibers in different muscles are presented in Table 4. In the soleus muscles, the TIF presented the largest proportion, followed by the TIIAF and TIIDF. In the plantar muscles, the TIIDF predominates, followed by the TIIAF, TIIBF and TIF, in the two ages analyzed. The EDL muscle showed a predominance of TIIBF. The gastrocnemius muscle, both lateral and medial, showed a predominance of TIIDF.

\section{Discussion}

There are different myosin isoforms that contribute to the diversity of fibers and muscle functions. The principal differences among myosin isoforms reside in the molecular heavy chain (MHC) [38]. There are diverse scientific methods capable of identifying the myosin isoforms, providing information about the heterogeneity of the muscle fibers. Methods such as mATPase, electrophoresis and immunohistochemistry help to increase our understanding about the diversity of muscle fiber types, and each of these techniques have their own characteristics. Analysis by the immunological method permits the classification of neonatal, embryonic, type I and II fibers MHC. However, it limits the characterization of the mosaic of fibers easily identified by mATPase. The electrophoresis technique permits the characterization of different types of MHC by the exact identification of the molecular weight of each specific 


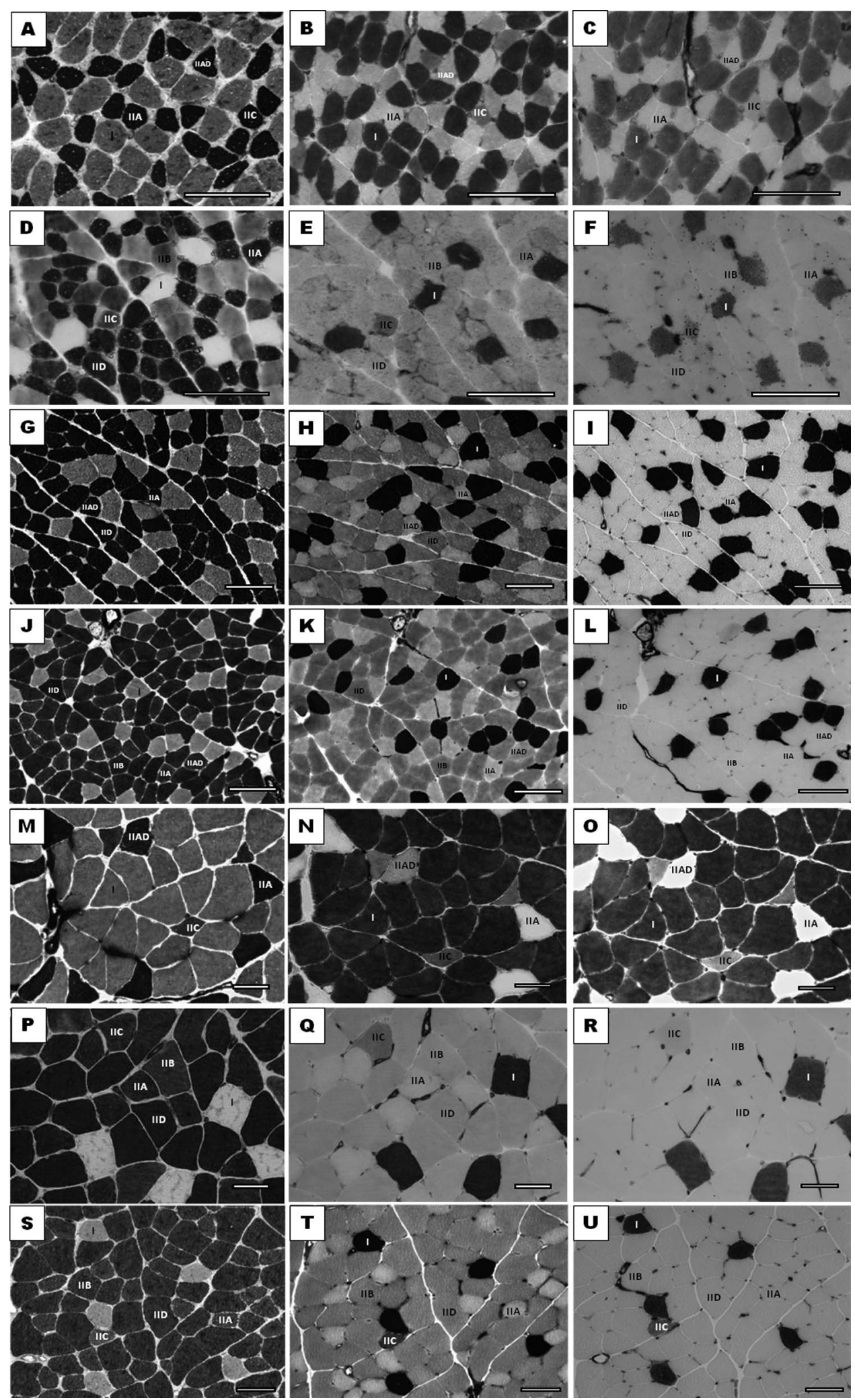

Fig. 1. Photomicrographs of muscle fragments processed by the mATPase reaction showing different pure and hybrid fibers in muscles selected for the study. A-C: Weanling soleus muscle: $\mathbf{A}$ in pH 9.8; $\mathbf{B}$ in pH 4.6; $\mathbf{C}$ in pH 4.3. D-F: Weanling plantar muscle: $\mathbf{D}$ in pH 10.4; $\mathbf{E}$ in pH 4.6; $\mathbf{F}$ in $\mathrm{pH}$ 4.4. G-I: Adult lateral gastrocnemius muscle: $\mathbf{G}$ in $\mathrm{pH}$ 9.9; $\mathbf{H}$ in pH 4.6; $\mathbf{I}$ in $\mathrm{pH}$ 4.3. J-L: Adult medial gastrocnemius muscle: $\mathbf{J}$ in $\mathrm{pH}$ 9.9; $\mathbf{K}$ in pH 4.6; $\mathbf{L}$ in pH 4.3. M-O: Adult soleus muscle: $\mathbf{M}$ in pH 9.4; $\mathbf{N}$ in pH 4.6; $\mathbf{O}$ in $\mathrm{pH}$ 4.3. $\mathbf{P}-\mathbf{R}$ : Adult plantar muscle: $\mathbf{P}$ in $\mathrm{pH} 10.4$; $\mathbf{Q}$ in $\mathrm{pH}$ 4.6; $\mathbf{R}$ in $\mathrm{pH}$ 4.3. S-U: Adult EDL muscle: $\mathbf{S}$ in $\mathrm{pH} 10.3$; $\mathbf{T}$ in $\mathrm{pH} 4.6$; $\mathbf{U}$ in $\mathrm{pH} 4.3$. Note that for all the muscles studied the $\mathrm{pH} 4.6$ value proved to be the most appropriate to define the largest spectrum of skeletal muscular tissue fiber. The alkaline values and the more acid complemented the classification of the rest of the fibers, pure and hybrid. Bars $=50 \mu \mathrm{m}$. 
Table 3. Means \pm standard deviation of lesser diameter $(\mu \mathrm{m})$ measurements in muscle fibers of female weanling ( $n=3)$ and adult ( $n=6)$ Wistar rats

\begin{tabular}{|c|c|c|c|c|c|c|c|}
\hline & \multicolumn{7}{|c|}{ Lesser diameter $(\mu \mathrm{m}) \pm \mathrm{SD}$ in different fibers } \\
\hline & TIF & TIICF & TIIACF & TIIAF & TIIADF & TIIDF & TIIBF \\
\hline $\mathrm{SOL}^{(\mathrm{W})}$ & $23.35 \pm 0.78$ & $17.66 \pm 0.86^{\mathrm{A}}$ & $18.85 \pm 0.66^{\mathrm{A}}$ & $19.21 \pm 1.41^{\mathrm{A}}$ & $18.70 \pm 1.06^{\mathrm{A}}$ & $19.7 \pm 2.37^{\mathrm{A}}$ & - \\
\hline $\operatorname{PLA}^{(\mathrm{W})}$ & $19.41 \pm 1.41$ & $15.92 \pm 1.24^{\mathrm{A} ; \mathrm{B}}$ & - & $16.60 \pm 1.37^{\mathrm{B}}$ & - & $16.64 \pm 0.12^{\mathrm{B}}$ & $19.78 \pm 0.32$ \\
\hline $\mathrm{GLD}^{(\mathrm{A})}$ & $31.49 \pm 4.98$ & $23.47 \pm 5.22$ & - & $24.97 \pm 3.69$ & $27.07 \pm 3.05$ & $29.43 \pm 3.34$ & - \\
\hline $\mathrm{GMD}^{(\mathrm{A})}$ & $34.54 \pm 3.16^{\mathrm{C}}$ & $28.92 \pm 6.69$ & - & $29.95 \pm 2.04$ & $32.21 \pm 3.14$ & $36.65 \pm 1.57^{\mathrm{C}}$ & $* *$ \\
\hline $\mathrm{SOL}^{(\mathrm{A})}$ & $42.61 \pm 4.01$ & $35.05 \pm 3.95^{\mathrm{A}}$ & $38.62 \pm 4.94$ & $36.54 \pm 3.28$ & $36.94 \pm 4.11$ & $35.09 \pm 4.91$ & - \\
\hline $\operatorname{PLA}^{(\mathrm{A})}$ & $36.29 \pm 2.56^{\mathrm{B}}$ & $* *$ & - & $32.56 \pm 1.32^{\mathrm{B}}$ & - & $38.91 \pm 1.70^{\mathrm{C}}$ & $41.68 \pm 1.98$ \\
\hline $\mathrm{EDL}^{(\mathrm{A})}$ & $23.60 \pm 1.58^{\mathrm{B}}$ & $25.19 \pm 4.94^{\mathrm{B}}$ & - & $24.20 \pm 2.65^{\mathrm{B}}$ & $24.74 \pm 3.94^{\mathrm{B}}$ & $30.18 \pm 3.72$ & $33.07 \pm 4.69$ \\
\hline
\end{tabular}

$\mathrm{SOL}^{(\mathrm{W})}$, soleus in weanling animals; PLA ${ }^{(\mathrm{W})}$, plantar in weanling rats; $\mathrm{GLD}^{(\mathrm{A})}$, lateral profound gastrocnemius in adult animals; $\mathrm{GMD}^{(\mathrm{A})}$, medial profound gastrocnemius in adult animals; $\mathrm{SOL}^{(\mathrm{A})}$, Soleus in adult animals; $\mathrm{PLA}^{(\mathrm{A})}$, plantar in adult animals; EDL ${ }^{(\mathrm{A})}$, extensor digitorum longus in adult animals. Tukey-Kramer $(\mathrm{p}<0.05):{ }^{\mathrm{A}} v s$ TIF; ${ }^{\mathrm{B}} v s \mathrm{TIIBF} ;{ }^{\mathrm{C}} v s$ TIIAF. $* *$ Present in some animals.

Table 4. Means \pm standard deviation of proportions (\%) of different fiber types evaluated in different muscles of female weanling ( $n=3$ ) and adult (n=6) Wistar rats

\begin{tabular}{lccccccc}
\hline & \multicolumn{7}{c}{ Types of fibers (\%) } \\
\cline { 2 - 8 } & \multicolumn{1}{c}{ TIF } & \multicolumn{1}{c}{ TIICF } & TIIACF & TIIAF & TIIADF & TIIDF & TIIBF \\
\hline SOL $^{(\mathrm{W})}$ & $49.01 \pm 5.86$ & $4.16 \pm 1.54^{\mathrm{a}}$ & $4.86 \pm 2.6^{\mathrm{a}, \mathrm{b}}$ & $33.8 \pm 12.85^{\mathrm{a}}$ & $7.97 \pm 4.56^{\mathrm{a}, \mathrm{b}}$ & $1.66 \pm 0.9^{\mathrm{a}}$ & - \\
PLA $^{(\mathrm{W})}$ & $9.37 \pm 1.39^{\mathrm{b}, \mathrm{d}, \mathrm{e}}$ & $1.28 \pm 0.62^{\mathrm{a}, \mathrm{b}, \mathrm{d}, \mathrm{e}}$ & - & $32.66 \pm 5.11^{\mathrm{d}}$ & - & $38.82 \pm 4.73$ & $18.16 \pm 5.6^{\mathrm{b}, \mathrm{d}}$ \\
GLD $^{(\mathrm{A})}$ & $21.72 \pm 7.63^{\mathrm{d}}$ & $4.13 \pm 2.25^{\mathrm{a}, \mathrm{c}, \mathrm{d}}$ & - & $13.66 \pm 6.74^{\mathrm{a}, \mathrm{d}}$ & $15.04 \pm 9.41^{\mathrm{a}, \mathrm{d}}$ & $56.49 \pm 9.04$ & - \\
GMD $^{(\mathrm{A})}$ & $15.2 \pm 6.47^{\mathrm{d}}$ & $2.67 \pm 0.05^{\mathrm{a}, \mathrm{b}, \mathrm{d}}$ & - & $14.53 \pm 5.72^{\mathrm{d}}$ & $14.06 \pm 5.79^{\mathrm{d}}$ & $56.41 \pm 11.06$ & $5.71 \pm 0^{\mathrm{d}}$ \\
SOL $^{(\mathrm{A})}$ & $54.28 \pm 6.25$ & $6.13 \pm 3.03^{\mathrm{a}, \mathrm{b}}$ & $2.8 \pm 1.78^{\mathrm{a}, \mathrm{b}, \mathrm{d}, \mathrm{d}}$ & $24.22 \pm 7.45^{\mathrm{a}}$ & $8.56 \pm 5.01^{\mathrm{a}, \mathrm{b}}$ & $9.97 \pm 6.9^{\mathrm{a}, \mathrm{b}}$ & - \\
PLA $^{(\mathrm{A})}$ & $8.69 \pm 3.27^{\mathrm{b}, \mathrm{d}, \mathrm{e}}$ & $0.74 \pm 0^{\mathrm{b}, \mathrm{d}, \mathrm{e}}$ & - & $22.83 \pm 4.47^{\mathrm{d}}$ & - & $49.56 \pm 7.12$ & $18.76 \pm 10.22^{\mathrm{d}}$ \\
EDL $^{(\mathrm{A})}$ & $5.93 \pm 2.74^{\mathrm{b}, \mathrm{d}, \mathrm{e}}$ & $2.73 \pm 2.15^{\mathrm{b}, \mathrm{d}, \mathrm{e}}$ & - & $17.62 \pm 7.99^{\mathrm{e}}$ & $6.72 \pm 5.01^{\mathrm{b}, \mathrm{d}, \mathrm{e}}$ & $14.29 \pm 8.25^{\mathrm{e}}$ & $54.29 \pm 10.96$ \\
\hline
\end{tabular}

$\mathrm{SOL}^{(\mathrm{W})}$, soleus in weanling animals; PLA ${ }^{(\mathrm{W})}$, plantar in weanling rats; GLD ${ }^{(\mathrm{A})}$, lateral profound gastrocnemius in adult animals; $\mathrm{GMD}^{(\mathrm{A})}$, medial profound gastrocnemius in adult animals; $\mathrm{SOL}^{(\mathrm{A})}$, Soleus in adult animals; $\mathrm{PLA}^{(\mathrm{A})}$, plantar in adult animals; $\mathrm{EDL}^{(\mathrm{A})}$, extensor digitorum longus in adult animals. ${ }^{a} \mathrm{p}<0.05$ compared with TIF; ${ }^{\mathrm{b}} \mathrm{p}<0.05$ compared with TIIAF; ${ }^{\mathrm{c}} \mathrm{p}<0.05$ compared with TIIADF; ${ }^{\mathrm{d}} \mathrm{p}<0.05$ compared with TIIADF; ${ }^{\mathrm{e}} \mathrm{p}<0.05$ compared with TIIBF.

MHC. However, this method should be carried out on isolated muscle fibers or on transversal sections of the muscle fragment providing quantitative information in proportion to each MHC present in fibers or fragment section analyzed. Nevertheless, currently only the mATPase technique can generate an in situ map of the fiber spectrum characterizing pure fibers and hybrid fibers. Moreover, this technique has the benefit of low cost and usability, favoring analyses of the types and subtypes of fibers for those who investigate skeletal muscles.

Throughout the years our research group has studied muscles from female Wistar rats submitted to varying procedures such as disuse and overload. We have faced questions such as: what is the best $\mathrm{pH}$ value adopted to identify the pure and hybrid fibers? Other studies had the same questions, but they did not emphasize different $\mathrm{pH}$ values used simultaneously to characterize the different types of muscle fibers in the same animal.

In the present study we classified, through the application of different $\mathrm{pH}$ values $(9.8 ; 4.6 ; 4.3$-weanling rats 9.4 ; 4.6; 4.3-adult rats) fibers typed I, IIC, IIAC, IIA, IIAD and IID in the soleus muscle of both ages (21 and 70 days).
Punkt et al. [25] also used the histoenzymological technique for mATPase in the soleus muscle of 8-day-old Wistar rats, and classified the fibers only as type I and type II. This limited classification could be attributed to the $\mathrm{pH}$ values used by the authors, $\mathrm{pH} 4.3$ and $\mathrm{pH} \mathrm{9.4,} \mathrm{which} \mathrm{makes} \mathrm{it}$ impossible to identify other types of pure and hybrid fibers. On the other hand, Picquet et al. [24] classified and quantified different fibers of the soleus muscle in Sprague Dawley rats 23 days old, and they used diverse $\mathrm{pH}$ values $(4.2,4.3,4.45$, and 10.4). Their results were similar to the values found in the present study. Schuenke et al. [28] also showed similar results after analyzing the soleus muscle of the adult mouse $(21.9 \mathrm{~g})$. In these studies the authors identified six different types of fibers and observed a predominance of TIF, similar to our findings.

Muscle fibers are dynamic structures capable of altering their phenotype and volume under diverse conditions, such as for example, increasing or decreasing neuromuscular activity, mechanical loading or unloading, alterations in the hormonal profile (especially in the thyroid hormones) and aging [22]. Chopard et al. [8] and Schuenke et al. [28] showed that type I fibers in the soleus muscle presented 
higher predominance and size. The authors attribute this characteristic to the constant activation of this muscle during functional activities. Other authors suggest that antigravitational activity of the quadrupeds favors the activity of the soleus muscle in the development of static posture $[13,26]$. Thus, in weanling and adults, the data presented here corroborate with the above-cited findings. Another important characteristic identified in our study of adult soleus muscle was the presence of TIIADF and TIIDF. The hybrid and pure fibers containing MHCIId form were only described by spectrophotometer [30] which aided our findings, although there are no reports of this type of fiber by mATPase analysis in the literature.

Even though soleus and plantar muscles present anatomical proximity, they both seem to be distinctive in their cytoarchitectural and biochemical characteristics. In both of the ages, the deep part of the plantar muscle demonstrated a predominance of TIIDF and a low proportion of TIF. Roy et al. [27] and Fuller et al. [12] observed similar results to those presented here in adult animals using immunohistochemical and biochemical techniques, respectively. On the other hand, in adult mouse, Schuenke et al. [28] observed the predominance of TIIBF in the analysis in the deep and superficial parts of this muscle. In the current study, we only carried out an analysis in the deep part of the plantar muscle to demonstrate fibers with an oxidative and glycolytic characteristic and not just glycolytic fibers as in the superficial region. Additionally, a great similarity was observed between the diameter of the TIF and TIIBF in the plantar muscle of weanling rats. It can be suggested that adjustments in the enzymatic activity resulting from change in the functional demand could occur in the plantar muscle during this phase.

The activity of the succinate dehydrogenase enzyme (SDH) that indicates the oxidative profile of the muscle fibers was more accentuated in oxidative fibers when compared to glycolytic fibers, near the 75th day of the Wistar rat's life [25]. Schuenke et al. [28] reported a large area of transversal section in the TIIBF when compared to TIF in the plantar muscle of adult mouse. Moreover, in the deep portion of the plantar in adult rats, Nakatani et al. [19] showed that the TIIBF presents a larger area of transversal section in relation to TIF and TIIAF. This result is also valid for the tibial anterior muscle according to Staron et al. [34] and Cornachione et al. [9].

Besides the intrinsic differences between weanling and adult rats for the soleus and plantar muscles, differences were also observed within each group. The fibers of the same adult animals demonstrated a larger diameter when compared to the muscle fibers of weanling animals. This difference could be the result of the animal's growth with a subsequent increase in the functional demand after leaving the nest and the ending of the weaning phase [25]. Furthermore, the postnatal development is characterized by important changes in neuromuscular activity; in the maturation of the neuromuscular junction, in the excitation-contraction mechanism and a big increase in the levels of the thyroid hormone, which contributes to adequate muscular development $[1,25,37]$.

Another significant plantar flexor that has been highlighted in scientific literature is the gastrocnemius muscle. It is a dynamic muscle that acts during the impulsion phase of gait, even when compromising its function when submitted to procedures of disuse or when affected by neuromuscular illnesses. Therefore, in the plantar muscle, the present study opted to investigate the deep portion of both of the heads of the gastrocnemius muscle with the intention of identifying and classifying the different types of fibers that it is composed of.

Due to its presentation of intermittent contractions during gait, the gastrocnemius proves to be a muscle that is predominantly glycolytic. Our results showed a predominance of TIIDF in the lateral portion as well as in the medial portion of this muscle. Other studies, which analysed rats of different lineages also observed a higher concentration of this fiber type [11, 18]. Hämäläinen and Pette [15] observed a predominance of type IID fibers in the gastrocnemius muscle of rabbits. On the other hand, the same study demonstrated a predominance of type IIB fibers in the gastrocnemius muscle of mice, corroborating the findings of Erzen et al. [11] who studied this muscle in the Fischer 344 rat species. Controversial studies, such as those by Mattson et al. [18], showed an absence of this type of fiber in the medial portion of gastrocnemius. These parallel findings could possibly be justified by the different histochemical methods adopted and the different breeds and species studied.

When measuring the lesser diameter of the different types of fibers of gastrocnemius, the present study demonstrated that the lateral portion presents a similarity in the size of the fibers, while in the medial portion the TIF and TIIDF stand out by presenting a higher size when compared to the TIIAF. Staron et al. [34] studied Fischer 344 rats and also showed that type IID fibers presented a larger cross section area than the TIIAF and TIIADF fibers. In hamsters, the values for TIIDF were also larger than TIF, TIIAF and TIIBF [18].

With the function of an antagonist on the muscles studied herein, the EDL acts in fast and rhythmic phasic movements of dorsiflexion during gait [29]. It is considered a muscle of rapid contraction and so it is possible to find, in the scientific literature, a predominance of rapid contraction fibers [8]. Using the mATPase technique our research group could match the results obtained with other scientific studies. Our results showed a predominance of the type IIB fibers in the EDL muscle associated with the low proportion of TIF. Soukup et al. [31] and Larsson and Yu [16] also observed a predominance of TIIBF and a lower proportion of TIF in the EDL muscle of female Wistar rats. Other studies have observed this proportional difference between the TIF and TIIBF when the EDL muscle was analyzed in different animal lineages [3-5, 36, 39]. The present study showed higher values of the lesser diameter in fast contraction fibers than in other types. These data are in agreement with that published by Nakatani et al. [19], Staron et al. [34] 
and Cornachione et al. [9], in which, as has been described for the deep portion of the plantar muscle, the muscles of rapid contraction had rapid contraction fibers with a larger area than other fibers. There are no studies in scientific literature that deal with the proportion and size of different types of fibers in the gastrocnemius and EDL muscles of female Wistar rats.

In summary, the present study demonstrates that data obtained in the adult animals cannot always be applied to weanling animals of the same species. Although histochemical studies have been performed for decades, the classification of muscle fiber types and subtypes in different muscles of mammals of a young age and in adults still holds details that need careful evaluation.

\section{Acknowledgments}

The authors thank L. Neder, M. P. M. Scandar and D. L. C. Simões, Department of Pathology, FMRP-USP, for technical assistance. The authors wish to thank FAEPA for financial support and the graduate students L. C. B. de Oliveira, N. Padula and F. C. Freitas. A. C. MattielloSverzut is a CNPq Research Fellow.

\section{References}

1. Agbulut, O., Noirez, P., Beaumont, F. and Butler-Browne, G. (2003) Myosin heavy chain isoforms in postnatal muscle development of mice. Biol. Cell 95; 399-406.

2. Allen, D. L., Yasui, W., Tanaka, T., Ohira, Y., Nagaoka, S., Sekiguchi, C., Hinds, W. E., Roy, R. R. and Edgerton, V. R. (1996) Myonuclear number and myosin heavy chain expression in rat soleus single muscle fibers after spaceflight. J. Appl. Physiol. 81; 145-151.

3. Ansved, T., Ohlsson, A. L., Jakobsson, F. and Johansson, B. B. (1996) Enzyme-histochemical and morphological characteristics of fast- and slow-twitch skeletal muscle after brain infarction in the rat. J. Neurol. Sci. 144; 14-20.

4. Bigard, A. X., Boehm, E., Veksler, V., Mateo, P., Anflous, K. and Ventura-Clapier, R. (1998) Muscle unloading induces slow to fast transitions in myofibrillar but not mitochondrial properties. Relevance to skeletal muscle abnormalities in heart failure. $J$. Mol. Cell Cardiol. 30; 2391-2401.

5. Bobinac, D., Malnar-Dragojeviæ, D., Bajek, S., Soiæ-Vraniæ, T. and Jerkoviæ, R. (2000) Muscle fiber type composition and morphometric properties of denervated rat extensor digitorum longus muscle. Croat. Med. J. 41; 294-297.

6. Brooke, M. H. and Kaiser, K. K. (1970) Muscle fiber types: How many and what kind? Arch. Neurol. 25; 360-366.

7. Cartee, G. D. (1995) What insights into age-related changes in skeletal muscle are provided by animal models? J. Gerontol. A Biol. Sci. Med. Sci. 50; 137-141.

8. Chopard, A., Pons, F. and Marini, J. F. (2001) Cytoskeletal protein contents before and after hindlimb suspension in a fast and slow rat skeletal muscle. Am. J. Physiol. Regul. Integr. Comp. Physiol. 280; 323-330.

9. Cornachione, A., Cação-Benedini, L. O., Shimano, M., Volpon, J. B., Martinez, E. Z., Neder, L. and Mattiello-Sverzut, A. C. (2008) Morphological comparison of different protocols of skeletal muscle remobilization in female rats after hindlimb suspension. Scand. J. Med. Sci. Sports 18; 453-461.

10. Dubowitz, V. (1985) Muscle biopsy: a practical approach. In
"Definition of Pathological Changes Seen in Muscle Biopsies", 2nd ed., Ballière Tindall, London, pp. 82-101.

11. Erzen, I., Pernus, F. and Sirca, A. (1990) Muscle fibre types in the human vastus lateralis muscles: do symmetrical sites differ in their composition? Anat. Anz. 171; 55-63.

12. Fuller, P. M., Baldwin, K. M. and Fuller, C. A. (2006) Parallel and divergent adaptations of rat soleus and plantaris to chronic exercise and hypergravity. Am. J. Physiol. Regul. Integr. Comp. Physiol. 290; 442-448.

13. Gregor, R. J., Smith, D. W. and Prilutsky, B. I. (2006) Mechanics of slope walking in the cat: quantification of muscle load, length change, and ankle extensor EMG patterns. J. Neurophysiol. 95; 1397-1409.

14. Guth, L. and Samaha, F. J. (1969) Qualitative differences between actomyosin ATPase of slow and fast mammalian muscle. Exp. Neurol. 25; 138-152.

15. Hämäläinen, N. and Pette, D. (1993) The histochemical profiles of fast fiber types IIB, IID, and IIA in skeletal muscles of mouse, rat, and rabbit. J. Histochem. Cytochem. 41; 733-743.

16. Larsson, L. and Yu, F. (1997) Gender-related differences in the regulatory influence of thyroid hormone on the expression of myosin isoforms in young and old rats. Acta Physiol. Scand. 159; 81-89.

17. Mahon, M., Toman, A., Willan, P. L. and Bagnall, K. M. (1984) Variability of histochemical and morphometric data from needle biopsy specimens of human quadriceps femoris muscle. $J$. Neurol. Sci. 63; 85-100.

18. Mattson, J. P., Miller, T. A., Poole, D. C. and Delp, M. D. (2002) Fiber composition and oxidative capacity of hamster skeletal muscle. J. Histochem. Cytochem. 50; 1685-1692.

19. Nakatani, T., Nakashima, T., Kita, T., Hirofuji, C., Itoh, K., Itoh, M. and Ishihara, A. (2000) Cell size and oxidative enzyme activity of different types of fibers in different regions of the rat plantaris and tibialis anterior muscles. Jpn. J. Physiol. 50; 413418

20. Pernus, F. and Erzen, I. (1994) Fibre size, atrophy, and hypertrophy factors in vastus lateralis muscle from 18- to 29-year-old men. J. Neurol. Sci. 121; 194-202.

21. Pette, D. and Staron, R. S. (1997) Mammalian skeletal muscle fiber type transitions. Int. Rev. Cytol. 170; 143-223.

22. Pette, D. and Staron, R. S. (2000) Myosin isoform, muscle fiber types and transition. Microsc. Res. Tech. 50; 500-509.

23. Pette, D. and Staron, R. S. (2001) Transitions of muscle fiber phenotypic profiles. Histochem. Cell Biol. 115; 359-372.

24. Picquet, F., Stevens, L., Butler-Browne, G. S. and Mounier, Y. (1998) Differential effects of a six-day immobilization on newborn rat soleus muscles at two developmental stages. J. Muscle Res. Cell. Motil. 19; 743-755.

25. Punkt, K., Naupert, A. and Asmussen, G. (2004) Differentiation of rat skeletal muscle fibers during development and ageing. Acta Histochem. 106; 145-154

26. Roy, R. R., Hutchison, D. L., Pierotti, D. J., Hodgson, J. A. and Edgerton, V. R. (1991) EMG patterns of rat ankle extensors and flexors during treadmill locomotion and swimming. J. Physiol. (Lond.) 70; 2522-2529.

27. Roy, R. R., Kim, J. A., Monti, R. J., Zhong, H. and Edgerton, V. R. (1997) Architectural and histochemical properties of cat hip 'cuff' muscles. Acta Anat. (Basel) 159; 136-146.

28. Schuenke, M. D., Kopchick, J. J., Hikida, R. S., Kraemer, W. J. and Staron, R. S. (2008) Effects of growth hormone overexpression vs. growth hormone receptor gene disruption on mouse hindlimb muscle fiber type composition. Growth Horm. IGF Res. 18; 479-486.

29. Sawiska, U., Tyc, F., Kasicki, S. and Vrbová, G. (1996) Functional reorganization of the partially denervated hindlimb extensor and flexor muscle in rat. Acta Neurobiol. Exp. (Wars) 56; 441-447. 
30. Soukup, T., Vydra, J. and Cerný, M. (1979) Changes in ATPase and $\mathrm{SDH}$ reactions of the rat extrafusal and intrafusal muscle fibres after preincubations at different $\mathrm{pH}$. Histochemistry 60 ; 71-84.

31. Soukup, T., Smerdu, V. and Zachatová, G. (2009) Fiber type composition of unoperated rat soleus and extensor digitorum longus muscles after unilateral isotransplantation of a foreign muscle in long-term experiments. Physiol. Res. 58; 253-262.

32. Staron, R. S. and Pette, D. (1986) Correlation between myofibrillar ATPase activity and myosin heavy chain composition in rabbit muscle fibers. Histochemistry 86; 19-23.

33. Staron, R. S. and Pette, D. (1993) The continuum of pure and hybrid myosin heavy chain-based fibre types in rat skeletal muscle. Histochemistry 100; 149-153.

34. Staron, R. S., Kraemer, W. J., Hikida, R. S., Fry, A. C., Murray, J. D. and Campos, G. E. (1999) Fiber type composition of four hindlimb muscles of adult Fisher 344 rats. Histochem. Cell Biol. $111 ; 117-123$.

35. Stephenson, G. M. M. (2006) Diversity and plasticity of vertebrate skeletal muscle: insights from hybrid fibres. Braz. J. Morphol. Sci. 23; 187-194.

36. Stevens, L., Firinga, C., Gohlsch, B., Bastide, B., Mounier, Y. and
Pette, D. (2000) Effects of unweighting and clenbuterol on myosin light and heavy chains in fast and slow muscles of rat. Am. J. Physiol. Cell Physiol. 279; 1558-1563.

37. Sullivan, V. K., Powers, S. K., Criswell, D. S., Tumer, N., Larochelle, J. S. and Lowenthal, D. (1995) Myosin heavy chain composition in young and old rat skeletal muscle: effects of endurance exercise. J. Appl. Physiol. 78; 2115-2120.

38. Weiss, A., Schiaffino, S. and Leinwand, L. A. (1999) Comparative sequence analysis of the complete human sarcomeric myosin heavy chain family: implications for functional diversity. J. Mol. Biol. 290; 61-75.

39. Yajid, F., Mercier, J. G., Mercier, B. M., Dubouchaud, H. and Préfaut, C. (1998) Effects of $4 \mathrm{wk}$ of hindlimb suspension on skeletal muscle mitochondrial respiration in rats. J. Appl. Physiol. $84 ; 479-485$.

This is an open access article distributed under the Creative Commons Attribution License, which permits unrestricted use, distribution, and reproduction in any medium, provided the original work is properly cited 